\title{
Taurine Release by Astrocytes Modulates Osmosensitive Glycine Receptor Tone and Excitability in the Adult Supraoptic Nucleus
}

\author{
Katrina Y. Choe, ${ }^{1}$ James E. Olson, ${ }^{2}$ and Charles W. Bourque ${ }^{1}$ \\ ${ }^{1}$ Center for Research in Neuroscience, Research Institute of the McGill University Health Centre, Montreal General Hospital, Montreal, Quebec, Canada H3G \\ 1A4, and ${ }^{2}$ Department of Emergency Medicine/Department of Neuroscience, Cell Biology, and Physiology, Wright State University, Dayton, Ohio 45435
}

Cells can release the free amino acid taurine through volume-regulated anion channels (VRACs), and it has been hypothesized that taurine released from glial cells is capable of inhibiting action potential (AP) firing by activating neuronal glycine receptors (GlyRs) (Hussy et al., 1997). Although an inhibitory GlyR tone is widely observed in the brain, it remains unknown whether this specifically reflects gliotransmission because most neurons also express VRACs and other endogenous molecules can activate GlyRs. We found that VRACs are absent in neurons of the rat supraoptic nucleus (SON), suggesting that glial cells are the exclusive source of taurine in this nucleus. Application of strychnine to rat hypothalamic explants caused a depolarization of SON neurons associated with a decrease of chloride conductance and could excite these cells in the absence of fast synaptic transmission. This inhibitory GlyR tone was eliminated by pharmacological blockade of VRACs, by cellular taurine depletion, by metabolic inactivation of glia with fluorocitrate, and after retraction of astrocytic processes that intercalate neuronal somata and dendrites. Finally, GlyR tone varied inversely with extracellular fluid tonicity to mediate the osmotic control of AP firing by SON neurons. These findings establish taurine as a physiological gliotransmitter and show that gliotransmission is a spatially constrained process that can be modulated by the morphological rearrangement of astrocytes.

\section{Introduction}

Changes in extracellular osmolality cause proportional changes in the electrical activity of magnocellular neurosecretory neurons in the supraoptic nucleus (SON) to regulate the release of vasopressin (VP; an antidiuretic hormone) and oxytocin (OT; a natriuretic hormone in rodents) and thus promote body fluid homeostasis (Bourque, 2008). Specifically, hyperosmotic conditions excite SON neurons to promote VP/OT secretion and reduce blood osmolality, whereas hypo-osmotic conditions inhibit electrical activity and basal hormone secretion to elevate osmolality. Previous studies have shown that the excitation of SON neurons during hypertonicity is mediated by the intrinsic osmosensitivity of these cells (Oliet and Bourque, 1993a) and by excitatory synaptic inputs from other osmosensitive neurons (Leng et al., 1989). However, recent work has suggested that taurine release by astrocytes might contribute significantly to the inhibition

\footnotetext{
Received March 20, 2012; revised July 5, 2012; accepted July 13, 2012.

Author contributions: K.Y.C. and C.W.B. designed research; K.Y.C. and J.E.O. performed research; K.Y.C. and J.E.O. analyzed data; K.Y.C. and C.W.B. wrote the paper.

This work was supported by Canadian Institutes of Health Research Operating Grants MOP-9939 and MOP-82818 to C.W.B., who was also the recipient of a James McGill Research Chair. The Research Institute of the McGill University Health Center was supported by the Fonds de la Recherche en Santé du Québec. We thank Denise Cook and Dr. Keith Murai for providing cultured astrocytes and Jim Leasure for help with the HPLC analysis.

Correspondence should be addressed to Charles W. Bourque, Center for Research in Neuroscience, Research Institute of the McGill University Health Centre, Montreal General Hospital, 1650 Cedar Avenue, Montreal, QC, Canada H3G 1A4. E-mail: charles.bourque@mcgill.ca.

DOI:10.1523/JNEUROSCI.1380-12.2012

Copyright $\odot 2012$ the authors $\quad 0270-6474 / 12 / 3212518-10 \$ 15.00 / 0$
}

of SON neurons via the activation of chloride flux through glycine receptors (GlyRs) under hypo-osmotic conditions (Hussy et al., 2000). Although this form of signaling could play an important role in the SON and other brain regions, the existence of taurinergic gliotransmission remains controversial.

The hypothesis that taurinergic gliotransmission might contribute to the osmotic control of SON neurons was developed around three main observations. First, it is well established that taurine is a potent agonist at GlyRs (Lynch, 2004), including those expressed on SON neurons (Hussy et al., 1997). Second, pharmacological blockade of GlyRs with strychnine can excite SON neurons during extracellular recordings in vivo, and this effect is augmented by lowering plasma osmolality (Hussy et al., 1997). Third, it has been shown that hypotonic solutions stimulate taurine release from isolated SON in vitro and that this effect is reduced by the glia-specific toxin fluorocitrate (FC) (Deleuze et al., 1998). Although these observations are consistent with the existence of taurinergic gliotransmission, important factors complicate this interpretation. For example, a recent study reported that the activation of chloride channels $\left(\mathrm{GABA}_{\mathrm{A}}\right.$ receptors) may have a depolarizing effect on VP neurons in the rat SON (Haam et al., 2012). If this is the case, the excitatory effects of locally applied strychnine observed in this nucleus would have to be caused by a blockade of GlyRs on local interneurons, rather than those on VP neurons themselves. Another factor confounding the taurinergic gliotransmission hypothesis is that two other agonists of GlyRs, namely glycine and $\beta$-alanine (Mori et al., 2002; Lynch, 2004), are present in the extracellular fluid (Shibanoki et al., 1993), and it is 
not known whether GlyRs are functionally activated by taurine or these other molecules in situ. Finally, it is well known that both neurons and glial cells can potentially release taurine (Olson and Li, 2000), making it difficult to establish whether any observable GlyR tone is mediated specifically by an agonist released from glial cells.

In this study, we used a combination of approaches to address these issues. Our results provide compelling evidence for the existence of taurinergic GlyR-dependent gliotransmission in the rat SON and reveal that this form of communication plays an important physiological role that relies on a spatially intimate relationship between neurons and surrounding astrocytes.

\section{Materials and Methods}

All procedures involving animals were performed according to protocol 1190 approved by the Facility Animal Care Committee of McGill University.

Electrophysiology in superfused hypothalamic explants. Acute hypothalamic explants were prepared from adult male Long-Evans rats (80-160 g) as described previously (Ghamari-Langroudi and Bourque, 2001) and superfused $(\sim 1 \mathrm{ml} / \mathrm{min})$ with warm $\left(31-33^{\circ} \mathrm{C}\right)$ oxygenated $\left(95 \% \mathrm{O}_{2} / 5 \%\right.$ $\mathrm{CO}_{2}$ ) artificial CSF (ACSF; pH 7.35) comprising (in mM) $104 \mathrm{NaCl}, 26$ $\mathrm{NaHCO}_{3}, 1.23 \mathrm{NaH}_{2} \mathrm{PO}_{4}, 3 \mathrm{KCl}, 1 \mathrm{MgCl}_{2}, 2 \mathrm{CaCl}_{2}, 10$ D-glucose, and mannitol added to the desired osmolality. Intracellular recordings were made via pipettes filled with $2 \mathrm{M}$ potassium acetate $(100-130 \mathrm{M} \Omega$ ). Steady-state voltage-current $(V-I)$ relationships were measured in the absence and presence of $1 \mu \mathrm{M}$ strychnine, and membrane conductance was determined as the inverse of the slope of the $V-I$ plot between -70 and $-60 \mathrm{mV}$. Reversal potential $\left(E_{\mathrm{REV}}\right)$ was determined from the intersection point of $V-I$ plots recorded in different conditions. We believe that the $E_{\mathrm{REV}}$ for chloride $\left(E_{\mathrm{Cl}}\right)$ is unaffected by our particular recording conditions ( $2 \mathrm{M} \mathrm{K}$ acetate, high-resistance sharp electrode, very low holding current). In an attempt to quantify this, we measured timedependent changes in IPSP reversal potential in a subset of neurons. No significant change was observed between the first and fifth minute $(-1.5 \pm 1.3 \mathrm{mV} ; n=3 ; p>0.05)$ or between the 5 th and 25 th minute $(+0.3 \pm 0.3 \mathrm{mV} ; n=3 ; p>0.05)$. Extracellular recordings of AP firing were made from preparations superfused with ACSF containing $4 \mathrm{~mm}$ $\mathrm{KCl}$ and $1 \mathrm{mM} \mathrm{CaCl}_{2}$ using micropipettes with lower resistance (15-20 $\mathrm{M} \Omega$ ) again filled with $2 \mathrm{M}$ potassium acetate, and the voltage signal was bandpass filtered between 600 and $1500 \mathrm{~Hz}$. Basal activity was determined as the average rate of firing observed during $3 \mathrm{~min}$ before application of strychnine. Changes in firing rate were calculated as the difference between basal activity and the average rate of discharge during the last $30 \mathrm{~s}$ of the strychnine application. Neurons with unstable baseline activity were excluded from the analysis.

Whole-cell patch-clamp recordings in slices. Coronal (transverse) hypothalamic slices (300 $\mu \mathrm{m}$ thick) were prepared from adult male LongEvans rats $(80-160 \mathrm{~g})$ as described previously (Trudel and Bourque, $2010)$ and perfused at $1.5 \mathrm{ml} / \mathrm{min}\left(31-33^{\circ} \mathrm{C}\right)$ with oxygenated $(95 \%$ $\mathrm{O}_{2} / 5 \% \mathrm{CO}_{2}$ ) ACSF comprising (in mM) $114 \mathrm{NaCl}, 26 \mathrm{NaHCO}_{3}, 1.23$ $\mathrm{NaH}_{2} \mathrm{PO}_{4}, 3 \mathrm{KCl}, 1 \mathrm{MgCl}_{2}, 2 \mathrm{CaCl}_{2}, 10 \mathrm{D}$-glucose, and 0.01 bicuculline. Whole-cell voltage-clamp recordings from SON neurons were performed using pipettes filled with a solution comprising (in $\mathrm{mM}$ ) 110 K-gluconate, 10 HEPES, $10 \mathrm{KCl}$, and $\mathrm{MgCl}_{2}$ (access resistance, 5.5-17.5 $\mathrm{M} \Omega$ ). Current-voltage analysis was performed on cells held at $-60 \mathrm{mV}$ using a $1 \mathrm{~s}$ voltage ramp command applied from -130 to $-45 \mathrm{mV}$. Membrane conductance was determined as the slope of the $I-V$ curve.

Volume-regulated anion channel recording in isolated neurons and glia. Mouse astrocyte cultures were prepared by triturating hippocampi removed from anesthetized postnatal day $0-2$ mice in glia growth medium comprising MEM supplemented with $1 \%$ penicillin, $0.6 \%$ glucose, and $10 \%$ horse serum (Invitrogen). Cultured astrocytes were replated onto Petri dishes $30 \mathrm{~min}$ before recording. Acutely isolated neurons were obtained from blocks of SON $\left(<1 \mathrm{~mm}^{3}\right)$ obtained from anesthetized LongEvans rats $(80-160 \mathrm{~g})$ and incubated in an oxygenated $\left(100 \% \mathrm{O}_{2}\right)$ PIPES solution containing $20 \mathrm{~mm} \mathrm{NaCl}, 5 \mathrm{~mm} \mathrm{KCl}, 1 \mathrm{~mm} \mathrm{MgCl}, 20 \mathrm{~mm}$ PIPES, $1 \mathrm{~mm} \mathrm{CaCl}_{2}, 10 \mathrm{~mm}$ D-glucose, $\mathrm{pH}$ 7.3, $0.5 \mathrm{mg} / \mathrm{ml}$ Protease-X, and 0.5 $\mathrm{mg} / \mathrm{ml}$ Protease-XIV at room temperature for $30 \mathrm{~min}$. Blocks rinsed in the enzyme-free PIPES solution were triturated, and the suspension was plated onto Petri dishes. For whole-cell patch clamp, electrodes (3-5 $\mathrm{M} \Omega$ ) were filled with a solution comprising (in mM) $110 \mathrm{CsCl}, 1 \mathrm{MgSO}_{4}$, 10 HEPES, and 1 EGTA; the $\mathrm{pH}$ was adjusted to 7.35 with $\mathrm{NaOH}$ and osmolality to $280 \mathrm{mOsm} / \mathrm{kg}$ with mannitol. Cells were superfused with a solution ( $\mathrm{pH} 7.4$ ) consisting of (in mM) $110 \mathrm{CsCl}, 2 \mathrm{CaCl}_{2}, 1 \mathrm{MgSO}_{4}$, and $10 \mathrm{HEPES}$; mannitol was added to $300 \mathrm{mOsm} / \mathrm{kg}$. Hypo-osmotic stimuli were applied by switching to HEPES lacking mannitol $(250 \mathrm{mOsm} / \mathrm{kg})$.

Chemicals and drugs. Strychnine $\mathrm{HCl}$ (Sigma-Aldrich) was dissolved in distilled water as a $1 \mathrm{~mm}$ stock and kept at $4^{\circ} \mathrm{C}$. 4- [(2-butyl-6,7-dichloro2-cyclopentyl-2,3-dihydro-1-oxo- $1 \mathrm{H}$-inden-5-yl)oxy] (DCPIB; Tocris Bioscience) was dissolved in DMSO at $5 \mathrm{~mm}$ concentration and kept at $-20^{\circ} \mathrm{C}$. These stocks were added directly to the ACSF as required for each experiment. Taurine (Sigma-Aldrich) was dissolved in ACSF at the concentration required. In taurine depletion experiments, guanodinoethane sulfonate (GES; Toronto Research Chemicals) was dissolved in ACSF (1 mM). For metabolic inactivation of glia, ACSF containing $65 \mu \mathrm{M}$ DL-fluorocitrate was prepared by precipitation of the barium salt of fluorocitric acid (SigmaAldrich). Synaptic blockade was achieved by adding $10 \mu \mathrm{M}(-)$-bicuculline methochloride (Sigma-Aldrich) and 2 mm kynurenic acid (Sigma-Aldrich) to the ACSF.

Immunohistochemistry. Coronal sections (50 $\mu \mathrm{m}$ thick) obtained using a vibratome were stained using antibodies against GlyRs (mAb4a mouse monoclonal antibody; Synaptic Systems) diluted 1:200 in PBS. Sections were then incubated in a fluorescent secondary antibody (Invitrogen; diluted 1:500), mounted in SlowFade Gold Antifade reagent (Invitrogen), and observed under a confocal laser-scanning microscope (Leica).

Electrophoresis and Western blotting. Equal amounts of SON tissue were triturated and homogenized in a HEPES-based buffer containing protease inhibitor (Roche) and 1.0\% Triton X-100 (Sigma-Aldrich) and incubated at $4^{\circ} \mathrm{C}$ for $30-60 \mathrm{~min}$. After centrifugation at $13,000 \mathrm{rpm}$ for $15 \mathrm{~min}$, protein concentration in the supernatant was measured using the Dc protein assay (Bio-Rad) and Ultrospec 2100 pro UV/visible spectrophotometer. Dithiothreitol (DTT) (Sigma-Aldrich) and a loading buffer containing bromophenyl blue (Sigma-Aldrich) were added to the supernatant and incubated at $80^{\circ} \mathrm{C}$ for $5 \mathrm{~min}$. Samples were loaded onto a NuPAGE $4-12 \%$ Bis-Tris gel (Invitrogen), and proteins were separated by electrophoresis at $150 \mathrm{~V}$ for $1 \mathrm{~h}$. Proteins were transferred to a PDVF membrane in transfer buffer (192 mm glycine, $25 \mathrm{~mm}$ Tris- $\mathrm{HCl}, 20 \%$ methanol, $\mathrm{pH} 8.3$ ) at $70 \mathrm{~V}$ for $1 \mathrm{~h}$. Membranes were blocked with Tris buffer containing $1 \%$ casein at $4^{\circ} \mathrm{C}$ overnight and incubated with the mAb4a antibody at 1:500 for $1 \mathrm{~h}$ and with HRP goat anti-mouse secondary antibody (1:5000; Cedarlane Laboratories Limited) for $30 \mathrm{~min}$. Detection was performed using an enhanced chemiluminescence kit (PerkinElmer Life and Analytical Sciences). Membranes were stripped by incubation with $100 \mathrm{~mm}$ glycine at $\mathrm{pH} 2.8$ for $30 \mathrm{~min}$ and probed with mouse anti-GADPH antibody (1:5000; Abcam) for normalization. The intensity of the bands was quantified using ImageJ analysis software (version 1.46; NIH).

Statistics. All values in this study are reported as mean plus or minus the SEM. Statistical differences between mean values were tested using Student's one-tailed, two-tailed, or paired $t$ test, as appropriate, with SigmaStat 2.03 software (SPSS). Comparisons of linear regression parameters were performed using Prism 5 software (GraphPad Software). Differences between values were considered to be significant when $p<0.05$.

\section{Results}

Although our study was designed to examine the regulation of VP neurons, we did not formally identify all of the SON neurons recorded as VP or oxytocin secreting. However, 70\% of SON neurons in Long-Evans rats are known to express VP, and all of our recordings were obtained from cells located in the most ventral part of the nucleus, which is composed almost exclusively of VP neurons (Rhodes et al., 1981). Many of the cells we recorded from were identified as putative VP-secreting neurons because they displayed spontaneous phasic firing (Poulain and Wakerley, 1982). 


\section{Neuronal GlyRs mediate inhibitory tone}

To determine whether strychnine can excite SON neurons in the absence of fast synaptic connectivity, we first examined the effects of bath-applied strychnine $(1 \mu \mathrm{M})$ during noninvasive single-unit extracellular recordings obtained from SON neurons in superfused explants of rat hypothalamus under conditions of synaptic blockade ( $2 \mathrm{~mm}$ kynurenic acid and $10 \mu \mathrm{M}$ bicuculline). To increase the physiological relevance, we performed these experiments at a slightly hypotonic $(275 \mathrm{mOsm} / \mathrm{kg})$ ACSF that is similar to the plasma osmolality of an animal experiencing systemic hypotonicity where strychnine-sensitive excitation is potentiated in vivo (Hussy et al., 1997). Application of strychnine under these conditions caused a significant increase in AP firing rate $(+1.04 \pm 0.3 \mathrm{~Hz} ; p=0.005 ; n=15$; Fig. $1 a)$, indicating that the excitatory effect of GlyR blockade persists in the absence of fast network synaptic activity. We also examined the effects of strychnine during intracellular voltage recordings. As expected, the strychnine-mediated excitation was associated with a significant depolarization of the membrane potential whether fast synaptic transmission was blocked (DNQX, APV, and gabazine; $+2.9 \pm$ $0.46 \mathrm{mV} ; n=3 ; p=0.024)$ or $\operatorname{not}(+1.79 \pm 0.66 \mathrm{mV} ; n=22 ; p=$ 0.013; Fig. $1 b, c)$.

To determine the mechanism of the strychnine-induced depolarization, we performed steady-state $V-I$ analysis (Fig. $1 d$ ). The depolarizing effect of strychnine was accompanied by a decrease of membrane conductance (from $6.87 \pm 0.65$ to $5.90 \pm$ $0.53 \mathrm{nS} ; n=6 ; p=0.012)$. The $E_{\mathrm{REV}}$ of strychnine's effect on membrane potential $(-58.7 \pm 4.3 \mathrm{mV} ; n=6)$ was equivalent to $E_{\mathrm{Cl}}$, as indicated by the $E_{\mathrm{REV}}$ of spontaneous inhibitory postsynaptic potentials observed in the same conditions $(-57.2 \pm 1.5$ $\mathrm{mV} ; n=14)$. Strychnine-induced changes in membrane conductance $(\Delta G)$ and $E_{\text {REV }}$ were not significantly different when measured in the presence of $10 \mu \mathrm{M}$ bicuculline $(\Delta G:-0.71 \pm 0.20 \mathrm{nS}$, $\left.n=5, p=0.58 ; E_{\mathrm{REV}}:-57.3 \pm 7.0 \mathrm{mV}, p=0.87, n=5\right)$, confirming that $\mathrm{GABA}_{\mathrm{A}}$ receptors do not participate in the above effect.

To confirm the presence of an inhibitory GlyR tone in VP neurons, we performed a subanalysis of the cells displaying phasic firing. We found that strychnine application caused a significant increase in intraburst firing rate $(\Delta,+39.2 \pm 12.7 \% ; p=0.008$; $n=14$ ), which indicates that GlyR-dependent tone is inhibitory. Moreover, 11 of 12 phasically active neurons studied by intracellular recording exhibited hyperpolarizing spontaneous IPSPs at voltages near AP threshold. Thus, GlyRs are tonically activated in SON neurons exposed to hypotonic ACSF. The blockade of these intrinsic GlyRs is sufficient to cause neuronal depolarization and excitation, including the VP-releasing population.

This finding is somewhat surprising, because a previous study using perforated patch-clamp recordings in hypothalamic slices reported that $E_{\mathrm{Cl}}$ lies above $\mathrm{AP}$ threshold in rat VP neurons (Haam et al., 2012). It is possible that the use of hypotonic ACSF could have altered $E_{\mathrm{Cl}}$ in some of our experiments. However, strychnine still excited SON neurons under isotonic conditions (see Fig. 7), and additional recordings performed in isotonic ACSF revealed $E_{\mathrm{Cl}}$ values equivalent to those observed in hypotonic conditions (our unpublished data). Recent work has shown that trauma caused by tissue slicing can alter chloride homeostasis in hippocampal neurons (Dzhala et al., 2012). Therefore, it is possible that results obtained from hypothalamic slices fail to reflect the polarity of chloride-dependent signaling in SON neurons in vivo. In contrast, our recordings were made from acute hypothalamic explants where the integrity of the SON remains relatively intact and where chloride homeostasis might better re- a
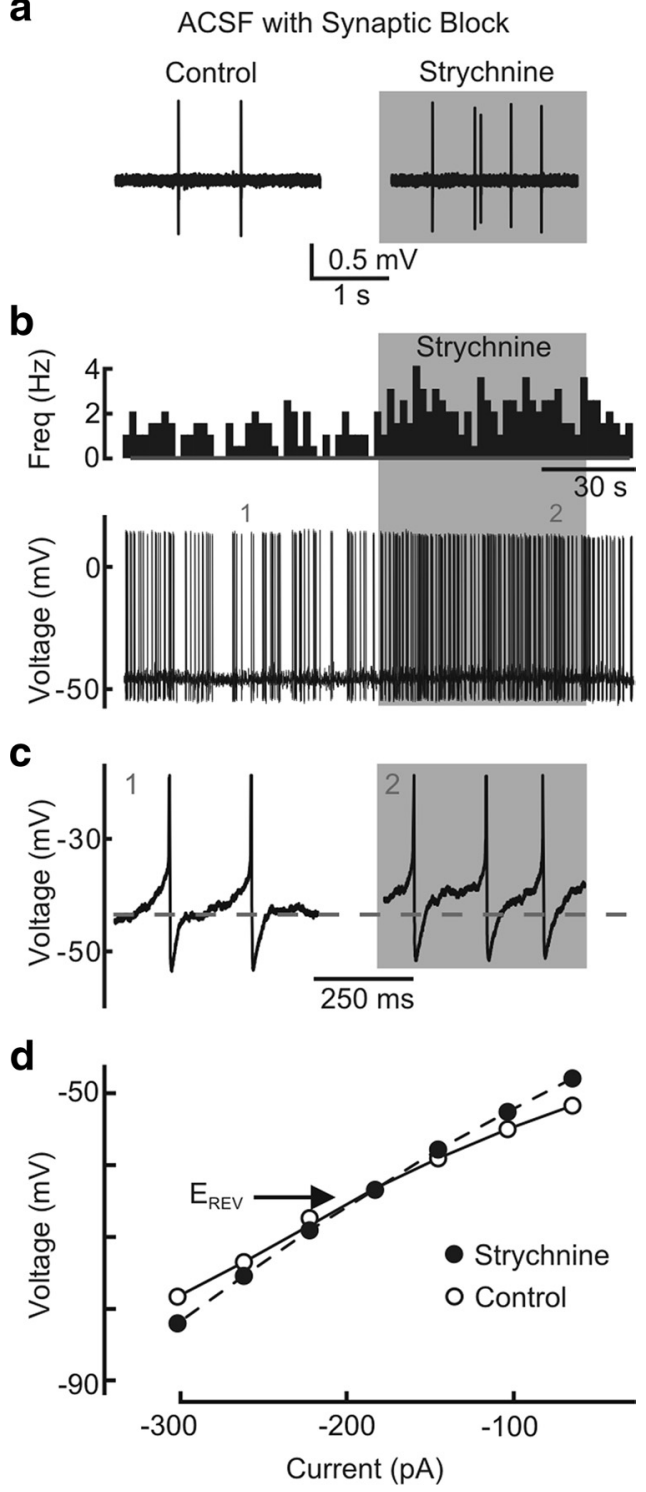

Figure 1. GlyRs mediate direct inhibitory tone on SON neurons. $\boldsymbol{a}$, Excerpts of single-unit extracellular recordings showing the effect of bath applying $1 \mu \mathrm{m}$ strychine on spontaneous AP firing rate in an SON neuron in a hypothalamic explant superfused with hypo-osmotic ACSF (275 $\mathrm{m} 0 \mathrm{sm} / \mathrm{kg}$ ) containing $2 \mathrm{~mm}$ kynurenic acid and $10 \mu \mathrm{m}$ bicuculline. $\boldsymbol{b}$, Traces show strychnineinduced changes in membrane voltage (bottom) and AP firing rate (Freq; top) measured by intracellular recording from an SON neuron in a hypothalamic explant. c, Excerpts taken from the cell in $\boldsymbol{b}$ before (1) and during (2) the application of strychnine. $\boldsymbol{d}$, Steady-state $V-/$ plot measured from an SON neuron in the absence (control) and presence of strychnine. The arrow points to the reversal potential $\left(E_{\mathrm{REV}}\right)$.

flect conditions in situ. Indeed, our results are in agreement with what has been observed in vivo for VP neurons (Hussy et al., 1997). Therefore, we believe that $E_{\mathrm{Cl}}$ normally lies negative of AP threshold in situ, allowing taurine to inhibit both VP- and OTsecreting neurons.

\section{GlyR tone is mediated by taurine}

To determine whether taurine is the agonist that specifically mediates tonic GlyR inhibition in the SON, we examined the effects of taurine depletion on basal firing rate and strychnine-mediated excitation (275 mOsm/kg ACSF). Taurine depletion was achieved by treating explants for $4 \mathrm{~h}$ with the selective taurine transport inhibitor GES $(40 \mu \mathrm{M})$ (Huxtable et al., 1979). Because 
a

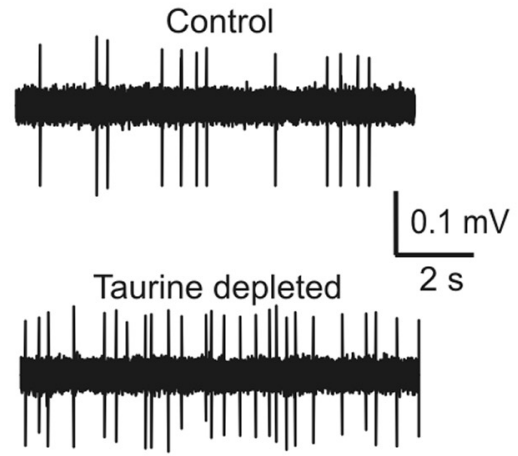

C
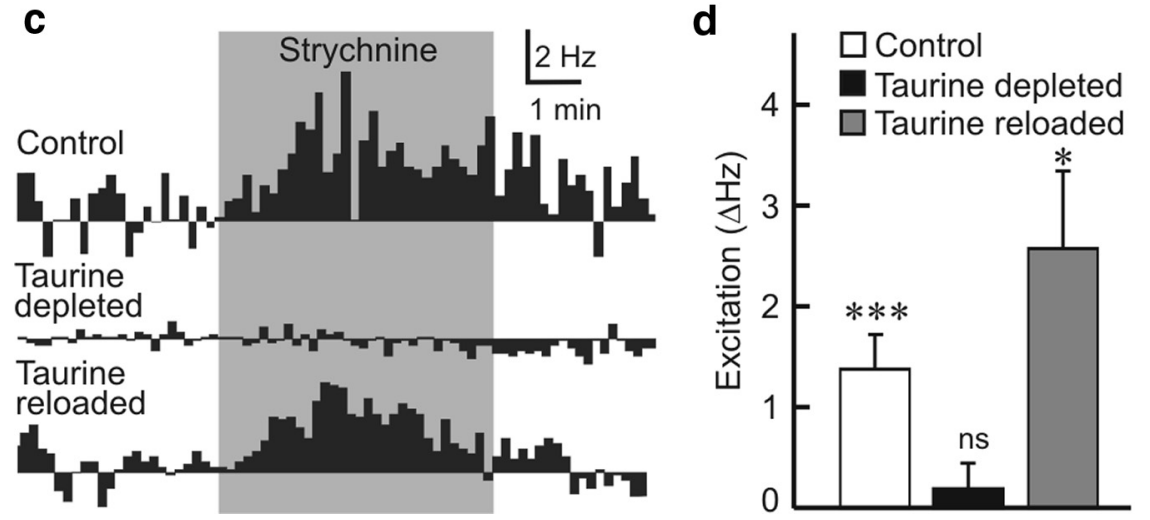

Figure 2. Taurine depletion abolishes GlyR tone in SON. $\boldsymbol{a}$, Excerpts from single-unit extracellular recordings illustrate basal firing rates of SON neurons recorded in a control preparation and in an explant depleted of taurine by application of GES (40 $\mu \mathrm{m} ; 4 \mathrm{~h})$. $\boldsymbol{b}$, Cumulative probability distributions of interspike intervals recorded from the cells shown in $\boldsymbol{a}$. $\boldsymbol{c}$, Rate-meter plots of representative extracellularly recorded single-unit firing (normalized to baseline) illustrate the effects of strychnine recorded in control, taurine-depleted, and taurine-reloaded preparations. $\boldsymbol{d}$, Bar graphs show the mean ( \pm SEM) strychnine-induced changes in firing rate (excitation) measured in different conditions. ${ }^{*} p<0.05 ;{ }^{* * *} p<0.005$. ns, Not significant.

GES also causes a reversible block of GlyRs (Sergeeva et al., 2002), explants were subsequently washed with GES-free ACSF for $>1 \mathrm{~h}$ before recording. Control experiments showed that neurons recorded under these conditions remain fully responsive to taurine. SON neurons recorded after taurine depletion (Fig. 2a,b) displayed a significantly higher basal firing rate $(2.69 \pm 0.44 \mathrm{~Hz}$; $n=16)$ compared with controls $(1.79 \pm 0.23 \mathrm{~Hz} ; n=28 ; p=$ 0.03 ), indicating that loss of tissue taurine had reduced a tonic inhibitory tone. Moreover, the excitatory effect of strychnine was eliminated in taurine-depleted preparations (Fig. $2 c$ ). In contrast to controls $(1.57 \pm 0.34 \mathrm{~Hz} ; n=28 ; p=0.00007)$, the firing rate of SON neurons recorded in these conditions was not affected by strychnine $(-0.19 \pm 0.25 \mathrm{~Hz} ; n=11 ; p=0.48$; Fig. 2d).

To establish the specificity of this effect, we examined whether reloading explants with taurine could restore the excitatory effect of strychnine. Taurine reloading was performed by bath application of $100 \mu \mathrm{M}$ taurine for $60 \mathrm{~min}$, followed by a >60 min wash with taurine-free ACSF. Indeed, the excitatory effect of strychnine was reestablished after taurine reloading $(\Delta, 2.57 \pm 0.77 \mathrm{~Hz} ; p=0.03$; $n=5$; Fig. $2 c, d)$, indicating that taurine is a specific mediator of the tonic GlyR tone on SON neurons.

GlyR tone is mediated by glial cells

Previous work has shown that both neurons and glia can release taurine via volume-regulated anion channels (VRACs) (Deleuze et al., 1998; Olson and Li, 2000; Pasantes-Morales et al., 2000) and that taurine efflux through these channels plays a key role in the protective regulatory volume decrease response that follows hypotonicity-induced swelling (Olson and Li, 2000; Pasantes-Morales et al., 2000). To determine whether VRACs mediate the taurine efflux responsible for tonic GlyR tone in the SON, we examined the effects of bath applying the selective VRAC inhibitor DCPIB (butanoic acid) (He et al., 2012). The excitatory effect of strychnine on SON neurons was eliminated in the presence of $40 \mu \mathrm{M}$ DCPIB $(-0.005 \pm 0.26 \mathrm{~Hz} ; p=0.98 ; n=8$; Fig. $3 a, b)$. Moreover, the basal firing rate of SON neurons recorded in the presence of DCPIB $(3.49 \pm 1.08 \mathrm{~Hz} ; n=8)$ was significantly greater than that observed in control neurons $(1.79 \pm 0.23 \mathrm{~Hz} ; n=28$; $p=0.032$; Fig. $3 b$ ), confirming that taurine efflux through VRACs is responsible for tonic GlyR tone in this nucleus.

Previous work has shown that neurons in the SON do not undergo swellinginduced regulatory volume decrease (Zhang and Bourque, 2003), a feature that may be important for their osmosensory properties (Zhang et al., 2007; Bourque, 2008). Therefore, we hypothesized that SON neurons do not express VRACs. To test this hypothesis, we compared the effects of an acute hypotonic stimulus $(-50$ $\mathrm{mOsm} / \mathrm{kg}$ ) on cultured astrocytes and acutely isolated SON neurons during whole-cell voltage-clamp recordings. In contrast to the astrocytes, which displayed a pronounced and significant increase in membrane conductance $(\Delta G$ in hypotonic solution, $+5.92 \pm 2.10 \mathrm{nS} ; p=0.02 ; n=10$; Fig. $3 c$ ), SON neurons did not display a significant increase in membrane conductance when exposed to the hypotonic stimulus but, rather, a near-significant decrease, as expected from previous work (Oliet and Bourque, 1993b) ( $\Delta G$ in hypotonic solution, $-0.90 \pm 0.40 \mathrm{nS} ; p=0.05 ; n=10$; Fig. $3 d$ ). Moreover, bath application of $40 \mu \mathrm{M}$ DCPIB suppressed the hypotonicityinduced conductance in cultured astrocytes $(-6.64 \pm 2.62 \mathrm{nS}$; $p=0.03 ; n=10$; Fig. $3 c$ ) but had no effect on hypotonicitytreated isolated SON neurons $(-0.61 \pm 0.45 ; \mathrm{ns}, p=0.11 ; n=$ 10; Fig. $3 d$ ). These results indicate that SON neurons do not express VRACs and suggest that taurine release in the SON is exclusively mediated by glial cells.

To confirm that taurine of glial origin is responsible for tonic GlyR tone in situ, we examined the effect of the glia-specific metabolic inhibitor FC $(65 \mu \mathrm{M})$ (Paulsen et al., 1987) on the excitatory action of strychnine in hypothalamic explants superfused with the hypotonic ACSF. As shown in Figure 3, $e$ and $f$, the strychnine-induced excitation $(+1.56 \pm 0.34 \mathrm{~Hz} ; p=0.00008$; $n=28)$ was eliminated in the presence of FC $(+0.01 \pm 0.18 \mathrm{~Hz}$; $p=0.95 ; n=10)$, and in agreement with the existence of tonic glia-mediated inhibition, the basal firing rate of neurons exposed to FC $(3.31 \pm 0.69 \mathrm{~Hz} ; n=10)$ was significantly greater than untreated neurons $(1.79 \pm 0.23 \mathrm{~Hz} ; n=28 ; p=0.011)$. The complete metabolic arrest of astrocytes by FC is also likely to interfere with the well described role of astrocytes in synaptic 
transmission, which may have contributed to the loss of strychnine-induced excitation. However, it is unlikely that this is the case because this effect was also observed when the blockade of fast synaptic transmission was achieved in the presence of $2 \mathrm{~mm}$ kynurenic acid and $10 \mu \mathrm{M}$ bicuculline $(-0.11 \mathrm{~Hz} ; p=0.81 ; n=14$; data not shown). This indicates that the loss of GlyR tone after metabolic inactivation of glial cells was not caused by a secondary change in synaptic activity through ionotropic AMPA and $\mathrm{GABA}_{\mathrm{A}}$ receptors.

Taurinergic gliotransmission is spatially confined

To determine whether the activation of neuronal GlyRs by glia-derived taurine is a spatially restricted or a more diffuse phenomenon, we compared the effect of strychnine on SON neurons in explants prepared from control (euhydrated) rats and animals that had been provided with $2 \% \mathrm{NaCl}$ as drinking fluid for $7 \mathrm{~d}$. Previous work has shown that chronic salt-loading induces a retraction of the astrocyte processes that normally intercalate the somata and dendrites of SON neurons (Tweedle and Hatton, 1976), and this retraction impairs other forms of gliotransmission in the SON (Oliet et al., 2001). As shown in Figure 4 , strychnine-induced changes in membrane potential $(+1.78 \pm 0.66 \mathrm{mV} ; p=$ $0.013 ; n=22)$ and conductance $(-0.97 \pm$ $0.25 \mathrm{nS} ; n=6 ; p=0.01$ ) were absent in explants prepared from salt-loaded (SL) rats $(-0.22 \pm 0.73 \mathrm{mV}, p=0.77, n=10$; and $+0.11 \pm 0.24 \mathrm{nS}, n=10, p=0.67)$.

Electron microscopy has shown that the retraction of astrocyte processes induced by salt-loading recovers progressively when animals are allowed to rehydrate over a 2 week period (Miyata et al., 1994). Therefore, if the loss of GlyR tone in SL rats is caused specifically by a loss of spatial proximity between as astrocytic processes and neuronal membranes, then the recovery of GlyR tone after rehydration should follow a similar time course. As shown in Figure 5, strychnine-induced excitation returned progressively in explants obtained from post-SL animals that had been allowed to rehydrate for 7-21 d and was fully restored after 2 weeks.

The loss of gliotransmission in SL animals could have been caused by an acquired defect in taurine release or GlyR function. To determine whether this was the case, we first performed a HPLC analysis of taurine content and release in the SON. We found that total taurine content in the SON of SL animals was not lower than controls (control, $67.4 \pm 6.39 \mathrm{nmol} /$ $\mathrm{mg}, n=10 \mathrm{vs} \mathrm{SL}, 99.3 \pm 10.3 \mathrm{nmol} / \mathrm{mg}, n=9 ; p=0.02)$, and no significant differences were observed in either basal $(0.13 \pm$ $0.05 \mathrm{nmol} / \mathrm{min}, n=5$ vs SL $0.29 \pm 0.13 \mathrm{nmol} / \mathrm{min} ; n=3 ; p=$

c

e
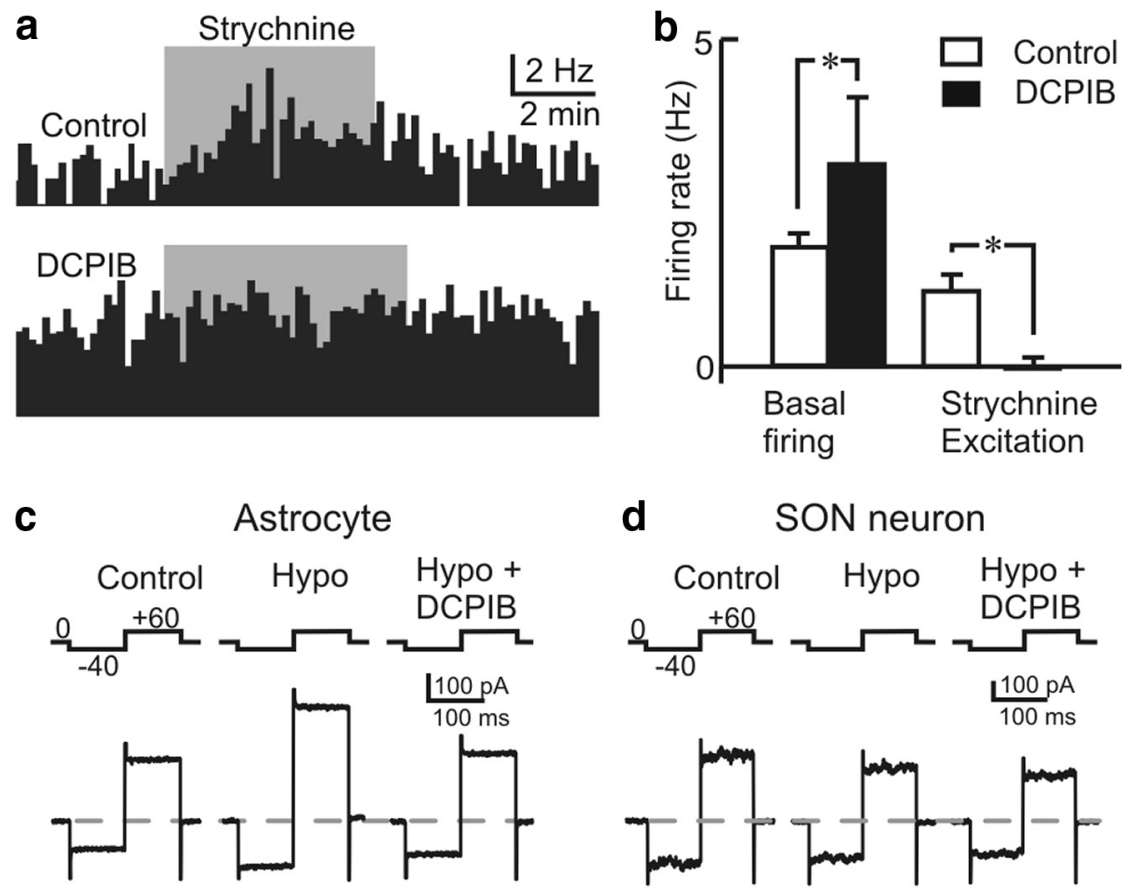

d SON neuron
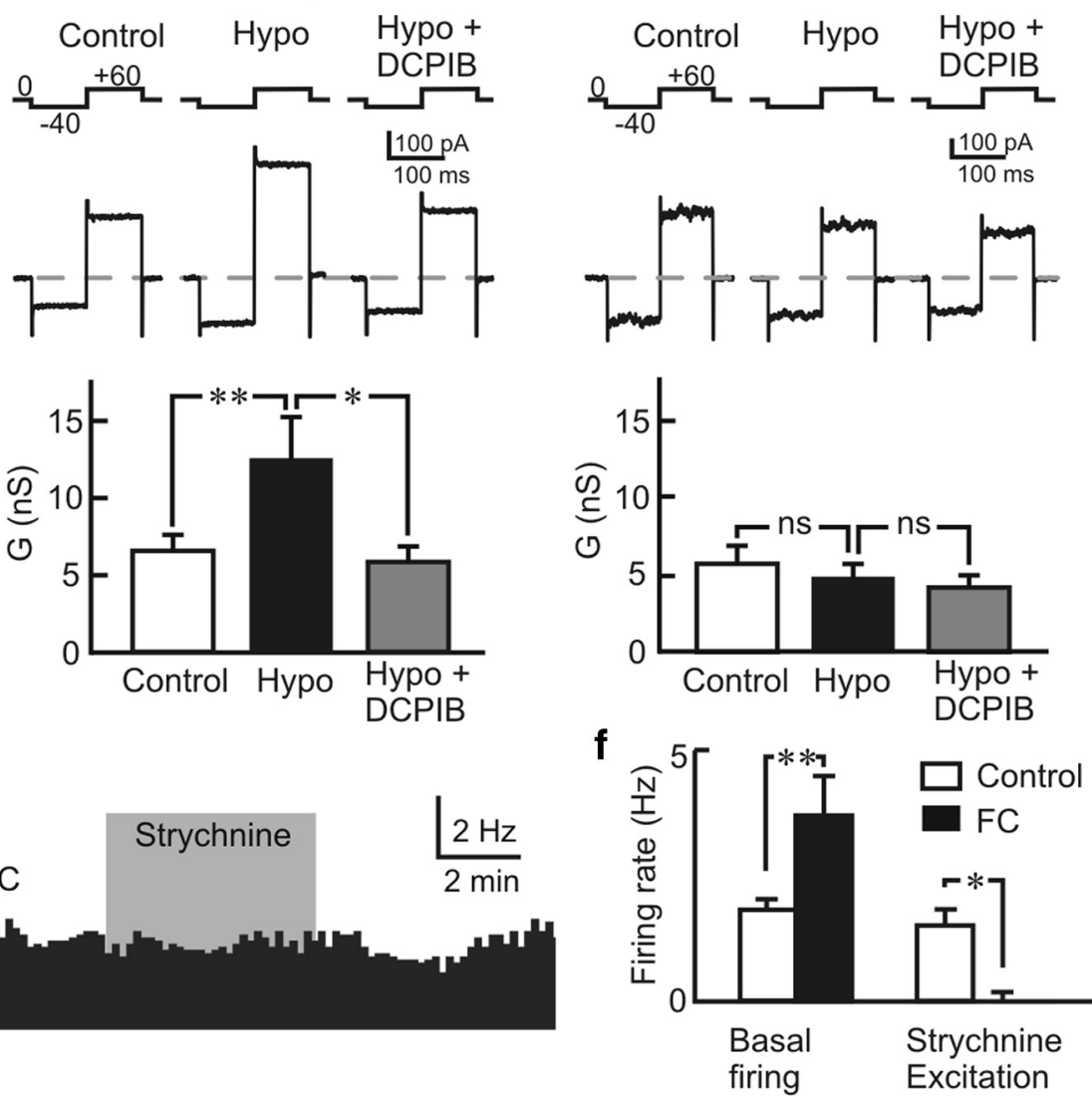

Figure 3. GlyR tone is mediated by VRACs in astrocytes. $\boldsymbol{a}$, Rate-meter plots of extracellularly recorded AP firing show the effects of $1 \mu \mathrm{m}$ strychnine on SON neurons in the absence (control) and presence of DCPIB (40 $\mu \mathrm{m}) . \boldsymbol{b}$, Bar graphs plot mean ( \pm SEM) values of basal firing rate and strychnine-induced excitation in groups of neurons ( ${ }^{*} p<0.05$ ). c, Current responses (bottom) to voltage commands (indicated above the left trace) applied to an isolated astrocyte in the absence (control) or presence of a hypotonic stimulus (Hypo; $-50 \mathrm{m0smol} / \mathrm{kg}$ ) and after the addition of the VRAC inhibitor DCPIB. Mean ( \pm SEM) values of membrane conductance $(G)$ measured in a group of cells are shown at the bottom $\left({ }^{*} p<0.05\right.$; $\left.{ }^{* *} p<0.01\right)$. $\boldsymbol{d}$, Effects of hypotonicity and DCPIB on isolated SON neurons (same layout as $c ; n s$, not significant). $\boldsymbol{e}$, Rate-meter plots of extracellularly recorded action potential firing show the effects of $1 \mu \mathrm{m}$ strychnine on SON neurons in the absence (control) and presence of FC $(65 \mu \mathrm{m} ; 5 \mathrm{~h})$. $f$, Bar graphs plot mean ( \pm SEM) values of basal firing rate and strychnine-induced excitation in groups of neurons recorded in each condition $\left({ }^{*} p<0.05 ;{ }^{* *} p<0.01\right)$.

0.21) or hypotonicity-induced taurine release by SONs isolated from control or SL rats $(0.59 \pm 0.11 \mathrm{nmol} / \mathrm{mg}, n=5 \mathrm{vs} \mathrm{SL}, 0.76 \pm$ $0.14 \mathrm{nmol} / \mathrm{mg}, n=3 ; p=0.40$; Fig. $6 a)$. Moreover, immunohistochemical analysis showed no difference in the staining intensity of SON neurons labeled with an anti-GlyR antibody in these two conditions [control, $21.1 \pm 4.4$ arbitrary units (AU), $n=3$; SL, $26.3 \pm 4.3 \mathrm{AU}, n=3 ; p=0.44$; Fig. $6 b$ ), and no significant difference in total GlyR protein was detected by Western blot 
a

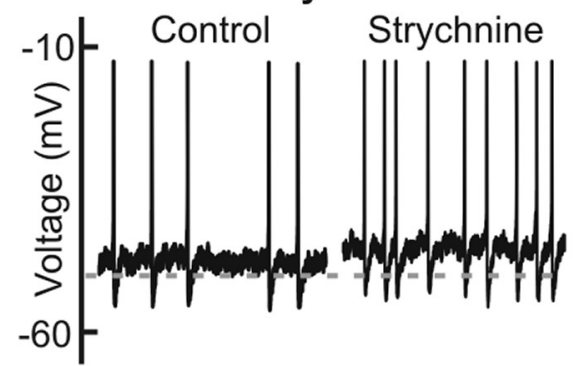

b
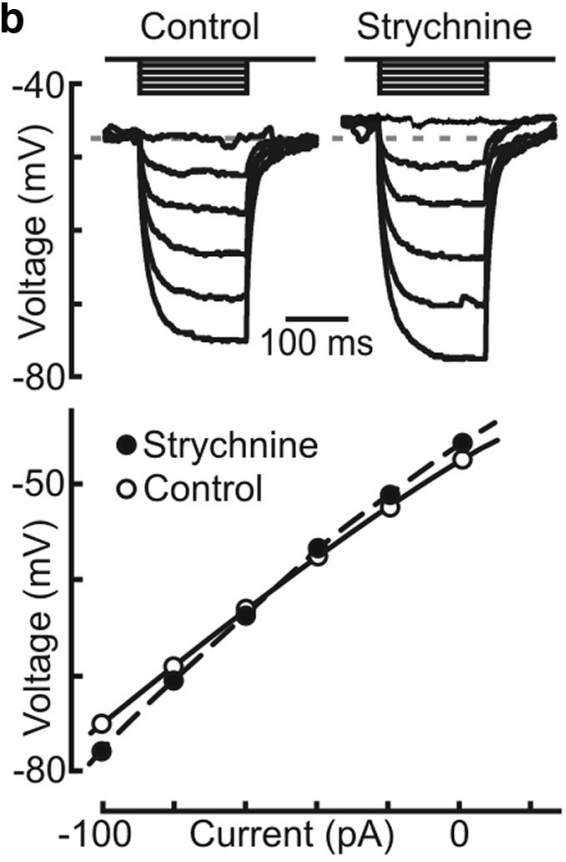

C

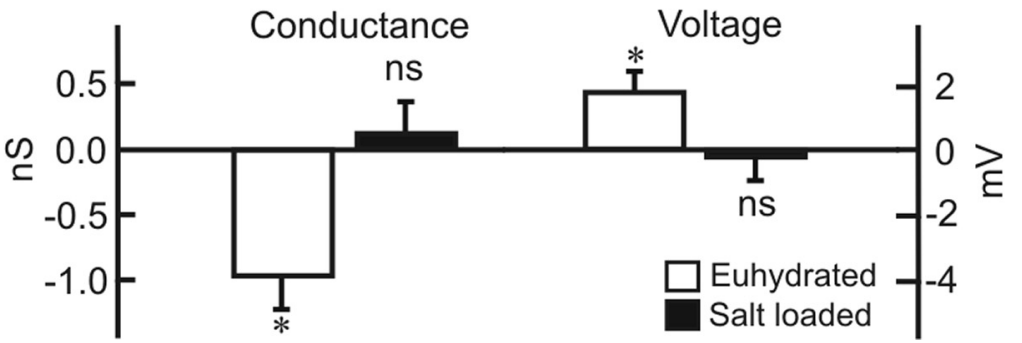

Figure 4. Chronic salt-loading eliminates GlyR tone. $\boldsymbol{a}$, Excerpts show membrane voltage in the absence (control) and presence of strychnine observed by intracellular recording in two SON neurons. Traces on the left are from an explant prepared from a euhydrated animal, and those on the right are from a rat subjected to chronic salt-loading. The dashed line indicates $-50 \mathrm{mV} . \boldsymbol{b}$, Voltage responses to current pulses (top) were used to construct voltage-current plots (bottom) in the absence and presence of strychnine. Data are from explants prepared from euhydrated (left) and salt-loaded (right) rats. c, Bar graphs plot mean ( $\pm S E M)$ changes in membrane conductance ( $\Delta G$; left) and membrane potential $\left(\Delta V_{\mathrm{m}}\right.$; right) induced by strychnine in euhydrated $(n=$ 22) and salt-loaded $(n=10)$ conditions. ${ }^{*} p<0.05$. ns, Not significant.

analysis of SONs obtained from control and SL rats (control, $2.4 \pm 0.5 \mathrm{AU}, n=4$; SL, $2.2 \pm 0.7 \mathrm{AU} ; n=4 ; p=0.88$; Fig. $6 c$ ). Finally, whole-cell patch-clamp recordings from $\mathrm{SON}$ neurons in hypothalamic slices failed to reveal any significant difference in $\Delta G$ induced by a saturating concentration of exogenous taurine (control, $+0.55 \pm 0.12 \mathrm{nS}, n=9 ; \mathrm{SL},+0.62 \pm 0.12 \mathrm{nS}, n=10 ; p=0.67$; Fig. $6 d$ ). Thus, taurine handling and GlyR function are unaltered in SL rats.

\section{GlyR tone varies inversely with fluid osmolality}

Previous studies have shown that VRAC-dependent taurine release is enhanced by hypotonicity and suppressed by hypertonic- ity (Deleuze et al., 1998; Olson and Li, 2000). To determine whether changes in osmolality have a functional impact on GlyR tone in the SON, we measured the excitatory effect of strychnine on neurons in explants superfused with ACSF adjusted to various osmolalities. We found that the intensity of the excitatory effect of strychnine varied as an inverse function of osmolality across the physiological range (Fig. 7a,b), including hypo-osmotic (275 $\mathrm{mOsm} / \mathrm{kg})$, isotonic $(300 \mathrm{mOsm} / \mathrm{kg})$, and hyperosmotic (325 and $350 \mathrm{mOsm} / \mathrm{kg}$ ) conditions. In contrast, strychnine had no significant effect on the activity of SON neurons in explants prepared from SL rats at any of the osmolality values tested in our experiments (Fig. $7 c, d$ ).

\section{Discussion}

Glycinergic neurotransmission is essentially absent in brain but serves as a major inhibitory synaptic mechanism in the spinal cord and brainstem (Kuhse et al., 1995). However, neurons in many parts of the brain express functional GlyRs, including those in cortex (Flint et al., 1998; Okabe et al., 2004), hippocampus (Mori et al., 2002; Chattipakorn and McMahon, 2003), midbrain (Ghavanini et al., 2006), and hypothalamus (Randle and Renaud, 1987; Hussy et al., 1997; Deleuze et al., 2005; Karnani et al., 2011). Previous work has shown that neurons in some of these areas become excited after exposure to strychnine (Hussy et al., 1997; Wang et al., 2005) and that the inhibitory tone revealed by this procedure can either emerge or be enhanced by conditions that promote an accumulation of extracellular glycine (Zhang et al., 2008) or taurine (Hussy et al., 1997). Thus, brain GlyRs can mediate a nonsynaptic inhibitory tone through an effect that is both plastic and region specific.

However, the cellular and molecular mechanisms that underlie the nonsynaptic GlyR tone have been difficult to define for two reasons. First, the identity of the ligand mediating this tone is unclear because three potential GlyR agonists are present in the extracellular fluid (ECF): alanine, glycine, and taurine (Lynch, 2004). Moreover, ambient concentrations of these molecules in bulk ECF appear to be subthreshold for the activation of GlyRs (Lerma et al., 1986; Nilsson et al., 1990; Whitehead et al., 2001). Thus, GlyR tone is likely generated in spatially constrained compartments where agonist concentrations are greater than those observed in bulk ECF. Second, the identity of the cells releasing functionally relevant GlyR agonists is difficult to establish because both neurons and glial cells can potentially contain (Adler, 1983) and release (Olson and $\mathrm{Li}, 2000$ ) such molecules.

Although VRACs can flux alanine, glycine, and taurine under basal conditions, previous studies have shown that hypotonicity 

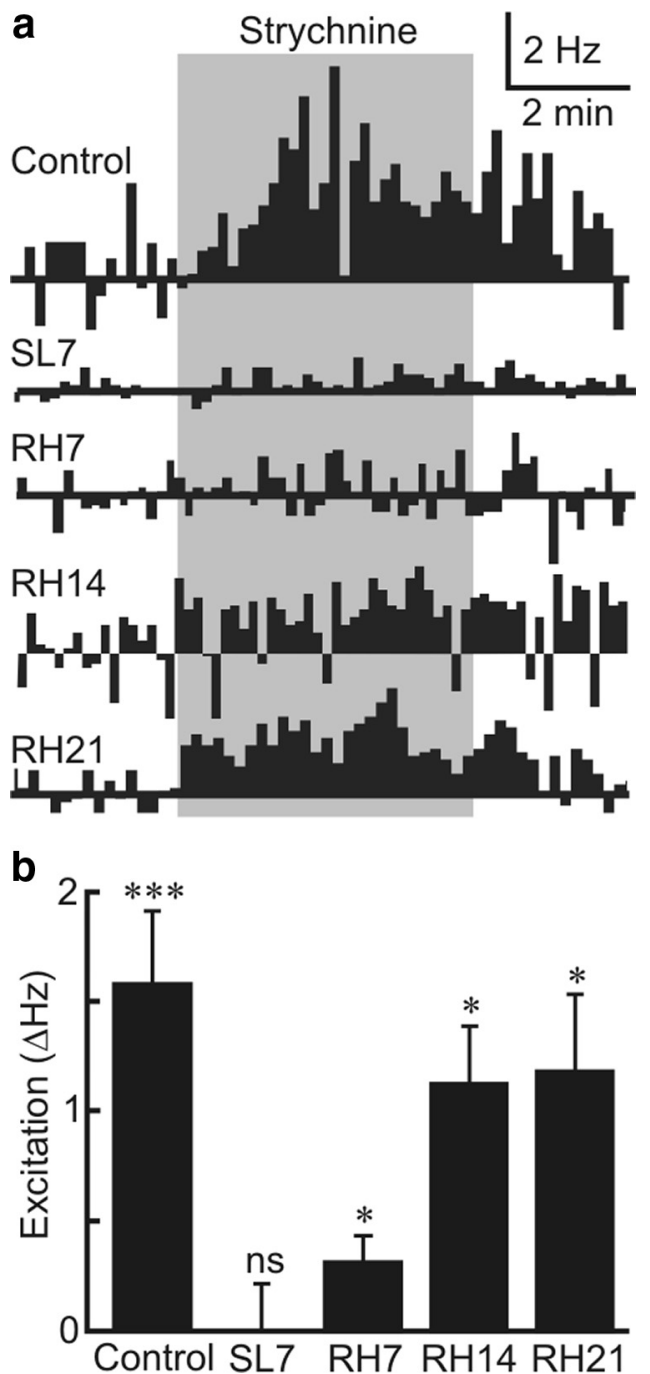

Figure 5. Recovery of gliotransmission after salt-loading. $\boldsymbol{a}$, Rate-meter plots of extracellularly recorded neuronal activity normalized to baseline illustrate the effects of strychnine on SON neurons in hypothalamic explants superfused with hypotonic solution $(275 \mathrm{~m} 0 \mathrm{sm} / \mathrm{kg})$. Traces are from controls, animals subjected to $7 \mathrm{~d}$ of salt-loading (SL7), or SL7 animals allowed to rehydrate for 7 (RH7), 14 (RH14), or 21 (RH21) days. $\boldsymbol{b}$, Bar graphs show mean ( \pm SEM) strychnine-induced excitation in all groups. Significant excitation was observed in all groups except SL7. The $p$ values are as follows: control, $0.00007(n=28) ; S L 7,0.99(n=24) ; \mathrm{RH7}$, $0.047(n=6) ; \mathrm{RH} 14,0.026(n=4) ; \mathrm{RH} 21,0.043(n=4)$ (paired $t$ test). ${ }^{*} p<0.05$; ${ }^{* * *} p<$ 0.005 . ns, Not significant.

causes a pronounced and proportional increase (3- to 10-fold) in the release of taurine, but not glycine or alanine (PasantesMorales et al., 1993; Hussy et al., 1997). Indeed, taurine is one of the most abundant free amino acids in brain (Huxtable, 1989), and biochemical studies have shown that intracellular taurine concentration can reach $20 \mathrm{~mm}$ in neurons and 30-50 mM in glia (Pasantes-Morales et al., 1993; Olson and Li, 2000). VRACdependent taurine release is therefore a strong candidate for the genesis of osmotically regulated taurine efflux and GlyR tone. The objectives of our study were to determine the cellular mediators of GlyR tone and to identify the nature of the molecule responsible for this effect in the SON.

Taurine mediates a hyperpolarizing GlyR tone in SON neurons

Our findings extend those of Hussy et al. (1997) by revealing that strychnine excites SON neurons via the direct inhibition of GlyRs

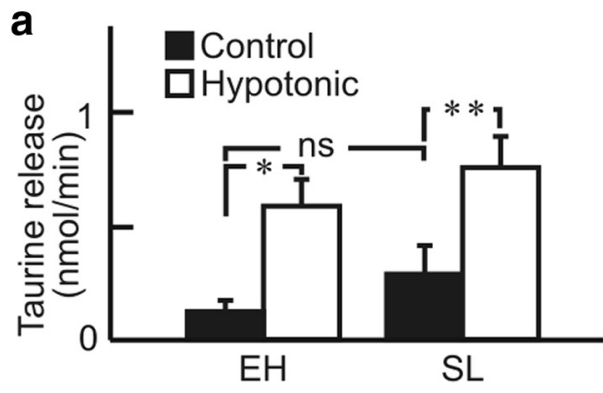

b $\quad \mathrm{EH}$

SL
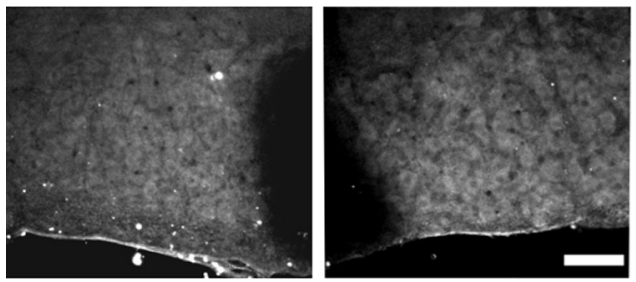

C

EH SL
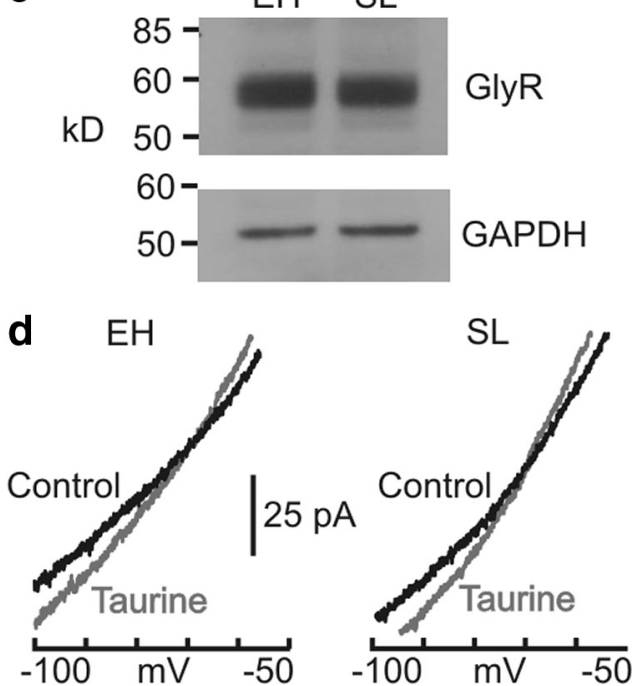

Figure 6. Salt loading does not affect taurine release or GlyR density. $\boldsymbol{a}$, Bar graphs show mean ( \pm SEM) rates of taurine release by isolated SONs in control ACSF and 13-15 min after switching to hypotonic ACSF $(250 \mathrm{~m} 0 \mathrm{sm} / \mathrm{kg})$ using tissue obtained from EH (left, $n=5)$ and SL $(n=3)$ animals. Basal release was not significantly different $(n s ; p=0.21)$, but hypotonicity significantly increased release in both control $\left({ }^{*} p=0.016\right)$ and SL $\left({ }^{* *} p=0.004\right)$ preparations. $\boldsymbol{b}$, Photomicrographs show examples of GlyR density observed by immunocytochemical staining of coronal sections through the SON of EH and SL rats (scale bar, $100 \mu \mathrm{m}$ ). c, Western blots show levels of GlyR and GAPDH detected in SONs isolated from EH and SL rats. $\boldsymbol{d}$, Traces show whole-cell current-voltage relationships measured by patch clamp from SON neurons in the absence (control) and presence of $5 \mathrm{~mm}$ taurine. Pairs of traces are from slices prepared from EH (left) and SL (right) rats.

expressed in these neurons rather than through a network effect involving presynaptic neurons (Fig. 1). As expected, the blockade of GlyRs led to a depolarization mediated by the suppression of a resting chloride conductance, and the $E_{\mathrm{REV}}$ for this effect was equal to that of IPSPs and negative to the threshold for AP generation. Moreover, selective depletion of tissue taurine by prolonged incubation in the presence of the taurine transport inhibitor GES (Morán et al., 1994) abolished the strychninemediated excitation and caused a significant increase in the basal firing rate of hypotonic SON neurons when compared with nondepleted preparations (Fig. 2). These results demonstrate that taurine is the specific agonist responsible for the chloride-dependent, 
a Euhydrated
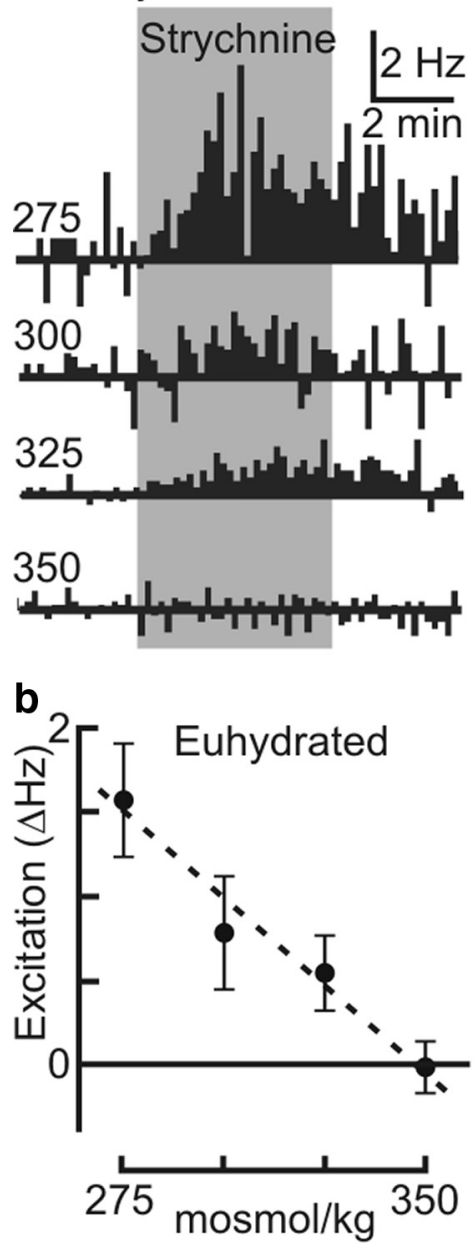

c Salt-loaded
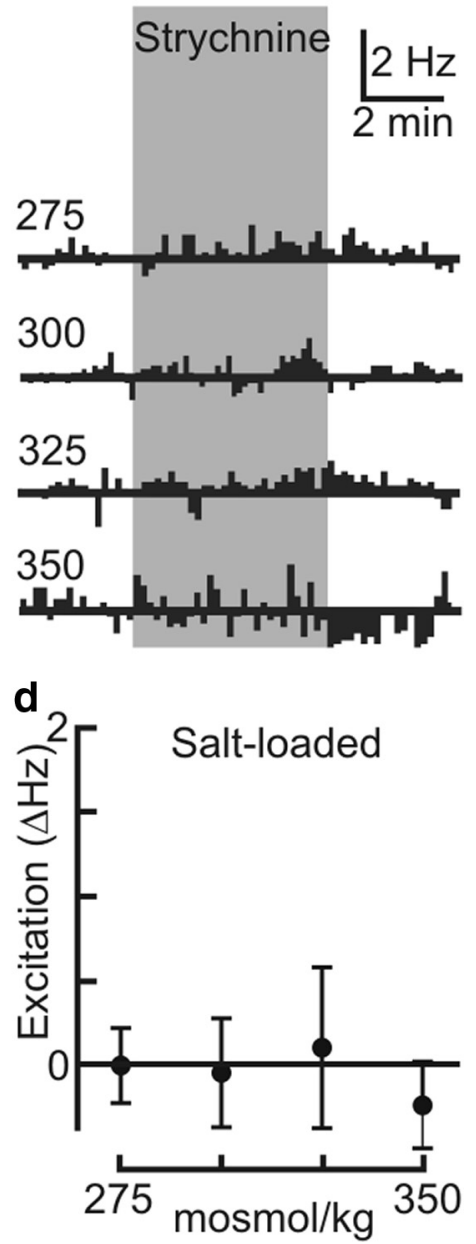

Figure 7. GlyR tone mediates osmoregulated firing in SON neurons. $\boldsymbol{a}$, Rate-meter plots of extracellularly recorded firing normalized to baseline show the effects of strychnine on the electrical activity of SON neurons recorded from explants obtained from euhydrated rats superfused with media of different osmolalities (values indicated at the left of each trace). $\boldsymbol{b}$, Plots show mean ( \pm SEM) strychnine-induced changes in firing rate (excitation) as a function of ACSF osmolality. The dashed line is a regression fit of the data (slope, $-0.021 \pm 0.007 \mathrm{~Hz} / \mathrm{m} 0 \mathrm{sm} \cdot \mathrm{kg}^{-1} ; p=0.0012 ; n=28,17,22$, and 4 for each point). $\boldsymbol{c}, \boldsymbol{d}$, Data obtained from salt-loaded animals treated in the same way. The slope of the regression in $\boldsymbol{d}$ was not different from zero (slope, $-0.0024 \pm 0.05 \mathrm{~Hz} / \mathrm{m0sm} \cdot \mathrm{kg}^{-1} ; p=0.57 ; n=24,14,7$, and 13 for each point).

hypotonicity-mediated inhibitory GlyR tone in SON neurons, including VP-releasing cells.

\section{GlyR tone reflects VRAC-dependent gliotransmission}

Both neurons and glial cells have been shown to contain taurine (Pasantes-Morales et al., 1993, 2000; Decavel and Hatton, 1995). GlyR tone could therefore result from taurine release by either or both types of cells. Interestingly, taurine is highly enriched in astrocytes compared with neuronal somata and dendrites in the SON (Decavel and Hatton, 1995). Moreover, it has been shown that SON neurons do not undergo regulatory volume decrease when exposed to hypotonicity (Zhang and Bourque, 2003), suggesting that these cells may not express VRACs. Experiments with the selective VRAC inhibitor DCPIB (Decher et al., 2001; Zhang et al., 2008; He et al., 2012) showed that GlyR tone in the SON is dependent on these channels (Fig. $3 a, b$ ), yet whole-cell patch-clamp experiments revealed that SON neurons fail to generate any DCPIB-sensitive conductance increase when exposed to hypotonicity (Fig. $3 c, d$ ), suggesting that GlyR tone is generated by taurine released specifically from glial cells in the SON.
This hypothesis was further supported by the absence of strychnine-mediated excitation in explants treated with the gliaspecific toxin FC (Fig. 3e,f). Moreover, physical retraction of astrocytic processes apposed to neuronal somata and dendrites during chronic salt-loading in vivo reversibly abolished GlyR tone in the SON (Figs. 4, 5). Several observations suggest that the loss of taurinergic gliotransmission during salt-loading was not related to a nonspecific effect of the protocol. First, loss of GlyR-dependent gliotransmission was also observed in explants prepared from lactating rats (data not shown), a completely distinct physiological state that also induces a profound retraction of astrocytic processes in this nucleus (Theodosis and Poulain, 1984). Second, the time course of recovery of GlyR tone was concurrent with the slow reestablishment of glial coverage after rehydration and not with the more rapid recovery of physiological parameters such as blood osmolality (Miyata et al., 1994). Third, loss of gliotransmission was not associated with a decline in SON taurine content, hypotonicity-induced taurine release (Fig. $6 a$ ), or a reduction in the GlyR density (Fig. $6 b-$ d). Therefore, we conclude that GlyR tone in the SON is caused specifically by VRAC-dependent taurine release from glial cells.

\section{Functional role of taurinergic gliotransmission in SON}

In agreement with the inverse relationship between osmolality and VRAC-mediated taurine release (Hussy et al., 1997), our findings revealed an inverse relationship between ECF osmolality and GlyR tone (Fig. 7). This finding is important because the physiological properties of SON neurons are known to vary in proportion with ECF osmolality, i.e., hypotonicity-induced hyperpolarization and the resulting suppression of firing activity (Voisin and Bourque, 2002). Taurinergic gliotransmission therefore contributes to the osmotic control of SON neurons by increasing the inhibitory impact of GlyRs, which reduces firing rate under hypo-osmotic conditions.

The loss of taurinergic gliotransmission observed during chronic salt-loading may also be physiologically important for survival. During the initial stages, this effect would remove entirely a potential source of inhibition under conditions where maximal AP firing and hormone release are required. Moreover, a recent study has shown that chronic salt-loading induces a positive shift of the $E_{\mathrm{Cl}}$ (Kim et al., 2011). The potential danger of this effect lies where an excitatory GlyR tone may emerge after acute rehydration, establishing a positive feedback process whereby an inappropriate rise in VP/OT release would lead to lifethreatening hyponatremia. The protracted loss of taurinergic gliotransmission induced by salt-loading may prevent this possibility by restoring the influence of the GlyR tone only after a hyperpolarizing chloride gradient is reestablished. 


\section{Possible role of taurinergic gliotransmission in other brain regions}

Since extrasynaptic GlyRs are expressed in many types of neurons, our results raise the possibility that taurinergic gliotransmission may also play a role in other parts of the brain. Indeed, taurine has been suggested to play a protective role during brain pathologies associated with swelling, such as ischemia (Benesova et al., 2009) and hyponatremia (Chvátal et al., 2007). In addition, neuronal hyperactivity can significantly increase extracellular $\left[\mathrm{K}^{+}\right]$(Gutnick et al., 1979), and elevated levels of extracellular $\left[\mathrm{K}^{+}\right]$can promote swelling-induced taurine release by surrounding glial cells (Pasantes-Morales and Schousboe, 1989). Taurinergic gliotransmission could therefore mediate feedback inhibition of neurons under hyperexcitable states associated with seizures and epilepsy. Indeed, taurine's protective role against epileptic activity is well documented (Pasantes-Morales et al., 1987).

Finally, the loss of GlyR tone after salt-loading indicates that a close spatial proximity between VRAC-containing astrocytic processes and neuronal membranes expressing GlyRs is required for this process. Indeed, taurine is efficiently transported from the extracellular compartment to the intracellular compartment via specific transporters (Huxtable, 1989). Therefore, we speculate that glial VRACs and neuronal GlyRs are normally located within local cell-cell "microdomains" where levels of extracellular taurine are sufficient for receptor activation. If this is the case, then it is possible that the retraction of astrocytic processes disrupts this relationship and that the spatial mismatch between taurine release and GlyRs prevents their activation because of the effect of distributed taurine uptake on bulk extracellular taurine levels. Interestingly, morphological astrocyte plasticity has been shown to occur in other parts of the brain [e.g., suprachiasmatic nucleus (Becquet et al., 2008), brain stem (Hirrlinger et al., 2004), and cortex (Jones et al., 1996)], and recent imaging studies have shown that astrocytic processes are highly motile and capable of extending and retracting on a time scale of minutes (Haber et al., 2006). Therefore, it is possible that taurinergic gliotransmission is a process that can be regulated dynamically in response to changes in astrocyte morphology.

\section{References}

Adler R (1983) Taurine uptake by chick embryo retinal neurons and glial cells in purified culture. J Neurosci Res 10:369-379.

Becquet D, Girardet C, Guillaumond F, François-Bellan AM, Bosler O (2008) Ultrastructural plasticity in the rat suprachiasmatic nucleus. Possible involvement in clock entrainment. Glia 56:294-305.

Benesova J, Hock M, Butenko O, Prajerova I, Anderova M, Chvatal A (2009) Quantification of astrocyte volume changes during ischemia in situ reveals two populations of astrocytes in the cortex of GFAP/EGFP mice. J Neurosci Res 87:96-111.

Bourque CW (2008) Central mechanisms of osmosensation and systemic osmoregulation. Nat Rev Neurosci 9:519-531.

Chattipakorn SC, McMahon LL (2003) Strychnine-sensitive glycine receptors depress hyperexcitability in rat dentate gyrus. J Neurophysiol 89:1339-1342.

Chvátal A, Anderová M, Hock M, Prajerová I, Neprasová H, Chvátal V, Kirchhoff F, Syková E (2007) Three-dimensional confocal morphometry reveals structural changes in astrocyte morphology in situ. J Neurosci Res 85:260-271.

Decavel C, Hatton GI (1995) Taurine immunoreactivity in the rat supraoptic nucleus: prominent localization in glial cells. J Comp Neurol 354:13-26.

Decher N, Lang HJ, Nilius B, BrüggemannA, Busch AE, Steinmeyer K (2001) DCPIB is a novel selective blocker of $\mathrm{I}(\mathrm{Cl}$,swell $)$ and prevents swellinginduced shortening of guinea-pig atrial action potential duration. $\mathrm{Br} \mathrm{J}$ Pharmacol 134:1467-1479.

Deleuze C, Duvoid A, Hussy N (1998) Properties and glial origin of osmotic-dependent release of taurine from the rat supraoptic nucleus. J Physiol 507:463-471.

Deleuze C, Alonso G, Lefevre IA, Duvoid-Guillou A, Hussy N (2005) Extrasynaptic localization of glycine receptors in the rat supraoptic nucleus: further evidence for their involvement in glia-to-neuron communication. Neuroscience 133:175-183.

Dzhala V, Valeeva G, Glykys J, Khazipov R, Staley K (2012) Traumatic alterations in GABA signaling disrupt hippocampal network activity in the developing brain. J Neurosci 32:4017-4031.

Flint AC, Liu X, Kriegstein AR (1998) Nonsynaptic glycine receptor activation during early neocortical development. Neuron 20:43-53.

Ghamari-Langroudi M, Bourque CW (2001) Ionic basis of the caesiuminduced depolarisation in rat supraoptic nucleus neurones. J Physiol 536:797-808.

Ghavanini AA, Mathers DA, Kim HS, Puil E (2006) Distinctive glycinergic currents with fast and slow kinetics in thalamus. J Neurophysiol 95:3438-3448.

Gutnick MJ, Heinemann U, Lux HD (1979) Stimulus induced and seizure related changes in extracellular potassium concentration in cat thalamus (VPL). Electroencephalogr Clin Neurophysiol 47:329-344.

Haam J, Popescu IR, Morton LA, Halmos KC, Teruyama R, Ueta Y, Tasker JG (2012) GABA is excitatory in adult vasopressinergic neuroendocrine cells. J Neurosci 32:572-582.

Haber M, Zhou L, Murai KK (2006) Cooperative astrocyte and dendritic spine dynamics at hippocampal excitatory synapses. J Neurosci 26:8881-8891.

He D, Luo X, Wei W, Xie M, Wang W, Yu Z (2012) DCPIB, a specific inhibitor of volume-regulated anion channels (VRACs), inhibits astrocyte proliferation and cell cycle progression via G1/S arrest. J Mol Neurosci 46:249-257.

Hirrlinger J, Hülsmann S, Kirchhoff F (2004) Astroglial processes show spontaneous motility at active synaptic terminals in situ. Eur J Neurosci 20:2235-2239.

Hussy N, Deleuze C, Pantaloni A, Desarménien MG, Moos F (1997) Agonist action of taurine on glycine receptors in rat supraoptic magnocellular neurones: possible role in osmoregulation. J Physiol 502:609-621.

Hussy N, Deleuze C, Desarménien MG, Moos FC (2000) Osmotic regulation of neuronal activity: a new role for taurine and glial cells in a hypothalamic neuroendocrine structure. Prog Neurobiol 62:113-134.

Huxtable RJ (1989) Taurine in the central nervous system and the mammalian actions of taurine. Prog Neurobiol 32:471-533.

Huxtable RJ, Laird HE 2nd, Lippincott SE (1979) The transport of taurine in the heart and the rapid depletion of tissue taurine content by guanidinoethyl sulfonate. J Pharmacol Exp Ther 211:465-471.

Jones TA, Hawrylak N, Greenough WT (1996) Rapid laminar-dependent changes in GFAP immunoreactive astrocytes in the visual cortex of rats reared in a complex environment. Psychoneuroendocrinology 21:189-201.

Karnani MM, Venner A, Jensen LT, Fugger L, Burdakov D (2011) Direct and indirect control of orexin/hypocretin neurons by glycine receptors. J Physiol 589:639-651.

Kim JS, Kim WB, Kim YB, Lee Y, Kim YS, Shen FY, Lee SW, Park D, Choi HJ, Hur J, Park JJ, Han HC, Colwell CS, Cho YW, Kim YI (2011) Chronic hyperosmotic stress converts GABAergic inhibition into excitation in vasopressin and oxytocin neurons in the rat. J Neurosci 31:13312-13322.

Kuhse J, Betz H, Kirsch J (1995) The inhibitory glycine receptor: architecture, synaptic localization and molecular pathology of a postsynaptic ionchannel complex. Curr Opin Neurobiol 5:318-323.

Leng G, Blackburn RE, Dyball RE, Russell JA (1989) Role of anterior peri-third ventricular structures in the regulation of supraoptic neuronal activity and neurohypophysial hormone secretion in the rat. J Neuroendocrinol 1:35-46.

Lerma J, Herranz AS, Herreras O, Abraira V, Martíndel Rio R (1986) In vivo determination of extracellular concentration of amino acids in the rat hippocampus. A method based on brain dialysis and computerized analysis. Brain Res 384:145-155.

Lynch JW (2004) Molecular structure and function of the glycine receptor chloride channel. Physiol Rev 84:1051-1095.

Miyata S, Nakashima T, Kiyohara T (1994) Structural dynamics of neural plasticity in the supraoptic nucleus of the rat hypothalamus during dehydration and rehydration. Brain Res Bull 34:169-175.

Morán J, Maar TE, Pasantes-Morales H (1994) Impaired cell volume 
regulation in taurine deficient cultured astrocytes. Neurochem Res 19:415-420.

Mori M, Gähwiler BH, Gerber U (2002) Beta-alanine and taurine as endogenous agonists at glycine receptors in rat hippocampus in vitro. J Physiol 539:191-200.

Nilsson P, Hillered L, Pontén U, Ungerstedt U (1990) Changes in cortical extracellular levels of energy-related metabolites and amino acids following concussive brain injury in rats. J Cereb Blood Flow Metab 10:631-637.

Okabe A, Kilb W, Shimizu-Okabe C, Hanganu IL, Fukuda A, Luhmann HJ (2004) Homogenous glycine receptor expression in cortical plate neurons and Cajal-Retzius cells of neonatal rat cerebral cortex. Neuroscience 123:715-724.

Oliet SH, Bourque CW (1993a) Steady-state osmotic modulation of cationic conductance in neurons of rat supraoptic nucleus. Am J Physiol 265:R1475-R1479.

Oliet SH, Bourque CW (1993b) Mechanosensitive channels transduce osmosensitivity in supraoptic neurons. Nature 364:341-343.

Oliet SH, Piet R, Poulain DA (2001) Control of glutamate clearance and synaptic efficacy by glial coverage of neurons. Science 292:923-926.

Olson JE, Li GZ (2000) Osmotic sensitivity of taurine release from hippocampal neuronal and glial cells. Adv Exp Med Biol 483:213-218.

Pasantes-Morales H, Schousboe A (1989) Release of taurine from astrocytes during potassium-evoked swelling. Glia 2:45-50.

Pasantes-Morales H, Arzate ME, Quesada O, Huxtable RJ (1987) Higher susceptibility of taurine-deficient rats to seizures induced by 4-aminopyridine. Neuropharmacology 26:1721-1725.

Pasantes-Morales H, Alavez S, Sánchez Olea R, Morán J (1993) Contribution of organic and inorganic osmolytes to volume regulation in rat brain cells in culture. Neurochem Res 18:445-452.

Pasantes-Morales H, Franco R, Torres-Marquez ME, Hernández-FonsecaK, Ortega A (2000) Amino acid osmolytes in regulatory volume decrease and isovolumetric regulation in brain cells: contribution and mechanisms. Cell Physiol Biochem 10:361-370.

Paulsen RE, Contestabile A, Villani L, Fonnum F (1987) An in vivo model for studying function of brain tissue temporarily devoid of glial cell metabolism: the use of fluorocitrate. J Neurochem 48:1377-1385.

Poulain DA, Wakerley JB (1982) Electrophysiology of hypothalamic magnocellular neurones secreting oxytocin and vasopressin. Neuroscience 7:773-808.

Randle JC, Renaud LP (1987) Actions of gamma-aminobutyric acid on rat supraoptic nucleus neurosecretory neurones in vitro. J Physiol 387:629-647.

Rhodes CH, Morrell JI, Pfaff DW (1981) Immunohistochemical analysis of magnocellular elements in rat hypothalamus: distribution and numbers of cells containing neurophysin, oxytocin, and vasopressin. J Comp Neurol 198:45-64.

Sergeeva OA, Chepkova AN, Haas HL (2002) Guanidinoethyl sulphonate is a glycine receptor antagonist in striatum. Br J Pharmacol 137:855-860.

Shibanoki S, Kogure M, Sugahara M, Ishikawa K (1993) Effect of systemic administration of N-methyl-D-aspartic acid on extracellular taurine level measured by microdialysis in the hippocampal CA1 field and striatum of rats. J Neurochem 61:1698-1704.

Theodosis DT, Poulain DA (1984) Evidence for structural plasticity in the supraoptic nucleus of the rat hypothalamus in relation to gestation and lactation. Neuroscience 11:183-193.

Trudel E, Bourque CW (2010) Central clock excites vasopressin neurons by waking osmosensory afferents during late sleep. Nat Neurosci 13:467-474.

Tweedle CD, Hatton GI (1976) Ultrastructural comparisons of neurons of supraoptic and circularis nuclei in normal and dehydrated rats. Brain Res Bull 1:103-121.

Voisin DL, Bourque CW (2002) Integration of sodium and osmosensory signals in vasopressin neurons. Trends Neurosci 25:199-205.

Wang F, Xiao C, Ye JH (2005) Taurine activates excitatory non-synaptic glycine receptors on dopamine neurones in ventral tegmental area of young rats. J Physiol 565:503-516.

Whitehead KJ, Manning JP, Smith CG, Bowery NG (2001) Determination of the extracellular concentration of glycine in the rat spinal cord dorsal horn by quantitative microdialysis. Brain Res 910:192-194.

Zhang LH, Gong N, Fei D, Xu L, Xu TL (2008) Glycine uptake regulates hippocampal network activity via glycine receptor-mediated tonic inhibition. Neuropsychopharmacology 33:701-711.

Zhang Y, Zhang H, Feustel PJ, Kimelberg HK (2008) DCPIB, a specific inhibitor of volume regulated anion channels (VRACs), reduces infarct size in MCAo and the release of glutamate in the ischemic cortical penumbra. Exp Neurol 210:514-520.

Zhang Z, Bourque CW (2003) Osmometry in osmosensory neurons. Nat Neurosci 6:1021-1022.

Zhang Z, Kindrat AN, Sharif-Naeini R, Bourque CW (2007) Actin filaments mediate mechanical gating during osmosensory transduction in rat supraoptic nucleus neurons. J Neurosci 27:4008-4013. 